\title{
The importance of timing of heat events for predicting the dynamics of aphid pest populations
}

\section{Running title: Complex nature of thermal consequences}

Fei Zhao ${ }^{1,2^{*}}$ Kun Xing ${ }^{1}$ Ary A. Hoffmann ${ }^{3}$ and Chun-sen Ma ${ }^{2 *}$

${ }^{1}$ Shanxi Key Laboratory of Integrated Pest Management in Agriculture, Institute of Plant Protection, Shanxi Academy of Agricultural Sciences, Taiyuan, Shanxi, China.

${ }^{2}$ Climate Change Biology Research Group, State Key Laboratory for Biology of Plant Diseases and Insect Pests, Institute of Plant Protection, Chinese Academy of Agricultural Sciences, Beijing, China.

${ }^{3}$ Pest and Environmental Adaptation Research Group, School of BioSciences, Bio21 Institute, The University of Melbourne, Victoria, Australia.

\section{Authors for correspondence:}

Chun-sen Ma:

Address: Yuan-Ming-Yuan West Road No.2, Beijing, 100193, P.R. China

Tel: (86) 1062811430

E-mail: machunsen@caas.cn

Fei Zhao:

81 Longcheng Street, Xiaodian District,Taiyuan 030031, P. R. China

Tel: +86 0351-7136636,

E-mail: zhaofei12@sxagri.ac.cn

This is the author manuscript accepted for publication and has undergone full peer review but has not been through the copyediting, typesetting, pagination and proofreading process, which may lead to differences between this version and the Version of Record. Please cite this article as doi: $10.1002 / p s .5344$

This article is protected by copyright. All rights reserved. 


\section{Author contributions}

C.-S.M. and F.Z. designed the study, F.Z. and K.X. performed the experiments. F.Z., A.A.H. and K.X. performed the statistical analysis. F.Z., C.-S.M. and A.A.H. wrote the first draft of the manuscript and all authors contributed substantially to revisions.

This article is protected by copyright. All rights reserved. 


\begin{abstract}
BACKGROUND: Heat waves are increasing in frequency and there is growing interest in their impact on pest organisms. Previous work indicates that effects depend on timing of the stress event whose impact needs to be characterized across the full set of developmental stages and exposure periods of an organism. Here we undertake such a detailed assessment using heat stress $\left(20-35{ }^{\circ} \mathrm{C}\right.$ diurnal cycle) across the nymph and adult stages of the English grain aphid, Sitobion avenae (Fabricius).

RESULTS: Stress-related mortality increased with stress duration at all stages; effects were less severe at the late nymphal stage. Longevity of adults after stress showed a complex pattern with nymphal heat stress, increasing with stress duration at the late nymphal stage but decreasing with duration at the early nymphal stage. Longevity was also reduced by adult stress but to a lesser extent and patterns were not connected to duration. Post-stress productivity decreased following adult and nymphal stress and the decrease tended to be correlated with stress duration. The rate of offspring production was more affected by adult stress than nymphal stress. Productivity and longevity effects when combined showed that the largest effect of heat stress occurred at the early nymphal stage.
\end{abstract}

This article is protected by copyright. All rights reserved. 
CONCLUSION: These findings highlight the complex ways in which heat stress at a particular life stage influences later fitness and they also emphasize the importance of considering multiple fitness components when assessing stress effects.

Key words: cereal aphid, climate change, fitness, heat selection, insect, life stage

\section{INTRODUCTION}

Global climate change is expected to increase not only mean temperature but also the intensity, frequency and duration of heat events ${ }^{1}$, which are projected to accelerate in the future ${ }^{2}$. For instance, during the crop-growing season of May at Beijing $\left(39^{\circ} 48 \mathrm{~N}\right.$, $116^{\circ} 28 \mathrm{E}$ ), a main winter wheat region in China, insect pests living in crop fields have been experiencing a marked increase in the number of hot days (daily maximum temperature exceeding $30^{\circ} \mathrm{C}$ ) over the last 45 years (Fig. S1A). Although mean temperatures in temperate areas are rarely expected to exceed optimum values for ectotherms ${ }^{3}$, even small shifts in mean temperature will substantially increase the incidence of extreme temperatures ${ }^{4,5}$ and more intense, more frequent, and longer lasting heat waves have been predicted ${ }^{6}$ resulting in stressful conditions for many ectotherms ${ }^{7-10}$ which may affect demographic rates ${ }^{11-13}$, phenology ${ }^{14}$, population dynamics ${ }^{15,16}$ and community structure ${ }^{17}$. In this context, species with relatively short generation times including most agricultural insects are increasingly likely to 
suffer one or more heat events of variable duration (Fig. S1B) at some point of their life cycle ${ }^{18,19}$.

The impacts of high temperature on insects are likely to be stage-specific, because the behavior ${ }^{20}$, thermal tolerance ${ }^{21-23}$, physiological measures ${ }^{24}$, developmental rates and metabolic rates ${ }^{25}$ following heat exposures vary ontogenetically in many taxa with complex life stages including Lepidoptera ${ }^{23,26,27}$, Diptera ${ }^{28-30}$, Coleoptera ${ }^{31,32}$, Odonata $^{33}$ and Blattaria ${ }^{34}$. High temperature effects can also vary across stages in organisms with relatively simple life-histories including Hemiptera ${ }^{35}$ and Homoptera 12, 18. Furthermore, high temperature effects at early stages in a life cycle can be carried over to later stages ${ }^{36}$ or even across generations ${ }^{37}$. Heat experienced in the egg stage may impact larval development ${ }^{38,39}$, as well as adult survival and body mass ${ }^{40}$ while heat experienced during early developmental stages can impact adult activity $^{41,42}$, size, coloration ${ }^{32}$ and reproduction ${ }^{13,18,26}$.

Despite recent progress in understanding stage-specific responses to high temperatures ${ }^{43,44}$, there is only limited information about the consequences of heat exposure when stress is applied in ecologically-relevant ways ${ }^{45}$, such as a series of consecutively hot days ${ }^{12,13}$. Indeed, the effect of different timescales - duration and pattern of thermal exposure - on ectotherms thermal performance and fitness ${ }^{46}$ has been ignored (but see ${ }^{47}$. In most previous studies, life-stages only experienced a bout 
of brief heat with variable ramping rates ${ }^{31,35}$, intensities ${ }^{23,29}$ or exposure times ${ }^{18,26}$. Repeat bouts of exposure may well produce results different from a single exposures given the potential for accumulated damage ${ }^{48}$. In many studies on thermal stress, constant temperatures are applied ${ }^{19,25,41}$ which could incorrectly estimate behavior ${ }^{49}$, thermal tolerance ${ }^{38,50-52}$ metabolic rate ${ }^{53}$, development ${ }^{39}$, and body mass ${ }^{38}$ as well as fitness performance ${ }^{54}$. High constant temperatures prevent repair from heat lesions during mild intervening conditions, potentially underestimating thermal responses ${ }^{55}$, 56. On the other hand, the negative impacts of daily maximum temperatures might be overlooked if constant conditions minimize mortality ${ }^{57,58}$. Therefore, studies on the effects of ecologically relevant variability in temperature including heat waves on thermal physiological performance and fitness are important ${ }^{59}$. Studies that incorporate more complex thermal regimens are necessary to predict acclimation capacities and/or evolutionary adaptation of thermal sensitivity in nature ${ }^{60}$. In evaluating the impact of heat events, temperatures need to vary in ecologically relevant ways ${ }^{59}$ and the effects of heat events of varying duration and timing need to be considered across life stages ${ }^{19}$.

Here we used the English grain aphid, Sitobion avenae (Fabricius), as a model species to investigate in detail the impact of different durations of heat stress during a life cycle, allowing temperatures to fluctuate and considering a range of fitness 
components. This aphid is an important global cereal pest common in temperate climates ${ }^{61}$ with a short life cycle ${ }^{62}$ which leads to overlapping generations and complex stage/age components in field populations. S. avenae populations usually peak in May around winter wheat crops of Beijing $\left(39^{\circ} 48 \mathrm{~N}, 116^{\circ} 28 \mathrm{E}\right)$ where a heat event involves consecutive hot days from one to five days duration (Fig. S1B). Given the increasing trend of heat events in the future, we created a series of heat events in which consecutive hot days from one to six days were simulated as daily cycles of sine-wave thermoperiods. The following questions are addressed. (1) What mortality patterns occur when heat stress occurs at different times and with different durations? (2) How are adult life history traits affected by heat stress periods at different times and of different durations, and are all components affected in the same way? (4) How do these findings translate into overall fitness effects at the population level? Our results demonstrate that mortality increased with the duration of heat events, but this also depends on the timing of the stress periods. Offspring numbers were decreased by heat events, but the effects on different fitness components varied. Overall the largest effects of heat events occurred when aphids were exposed at the early nymph stage.

\section{MATERIALS AND METHODS}

\subsection{Stocks}


English grain aphids were collected from a winter wheat field near Beijing $\left(39^{\circ} 48 \mathrm{~N}\right.$, $\left.116^{\circ} 28 \mathrm{E}\right)$ as described by Zhao, Zhang, Hoffmann and $\mathrm{Ma}^{56}$, and then were reared on winter wheat seedlings at $22 \pm 0.5{ }^{\circ} \mathrm{C}, 50-60 \%$ relative humidity, and a photoperiod of $16 \mathrm{~L}: 8 \mathrm{D}$. Seedlings were replaced every week. Experiments were undertaken after this stock had been reared under these conditions for 2 years.

\subsection{Temperature regimes}

Daily temperature records for May in Beijing from 2014 to 2018 were downloaded from the China Meteorological Data Sharing Service System (Fig. S2A). The daily highest and lowest temperatures were used to set temperature fluctuations representing a hot day with a high minimum temperature and a normal day (Fig. S2A). These daily temperature changes of $20-35^{\circ} \mathrm{C}$ and $13-28^{\circ} \mathrm{C}$ were mimicked in two growth chambers (RXZ-280B, Jiangnan Ltd., China) (Fig. S2B) designated as "hot" and "normal" growth chambers. The temperature regimen in each growth chamber involved changes at hourly intervals, which were recorded at 20-minute intervals using temperature/humidity data loggers (U23 - 001, Onset Ltd., USA). Relative humidity in the chambers fluctuated from about $40 \%$ (during the day) to $60 \%$ (during the night). Photoperiod was set to $16: 8$ (L: D) with lights on from 5.00 to 21.00 hours. 
To clarify effects of the timing and duration of heat events, four timings [early nymph (NE), late nymph (NL), early adult (AE) as well as late adult (AL)] and six durations (1, 2, 3, 4, 5 and 6 consecutively hot days) were considered (Fig. 1).

\subsection{Experiment protocol}

At the beginning of the experiment, about 1250 newly born nymphs $(<6 \mathrm{~h})$ were placed individually in a rearing tube consisting of a $5 \mathrm{ml}$ plastic tube (diameter $15 \mathrm{~mm}$, length $55 \mathrm{~mm}$ ) with $0.6 \%$ agar solution in one-third of the tube holding a newly-excised wheat leaf. They were then divided into 25 groups with about 50 nymphs/group.

Twelve groups were used immediately for exposure to heat at the nymphal stage. Six of these groups were put into the hot day chamber and another six were maintained in the normal day chamber (day 0, $21.00 \mathrm{~h}$ ). On the next evening (day 1, $21.00 \mathrm{~h}$ ), one group from the hot day chamber was transferred to the normal day chamber; at the same time, a group in the chamber of normal day was moved into the hot day chamber. This pattern was continued for six days and resulted in 12 nymphal treatments of timing $\times$ duration (Fig.1, NE and NL). On $21.00 \mathrm{~h}$ of the $7^{\text {th }}$ day, all aphids were transferred into the normal day chamber and reared until the end of the experiment. The development and survival of nymphs were recorded twice a day at 
09.00 and $21.00 \mathrm{~h}$. When aphids had developed to the adult stage, the number of offspring and the survival of adults were checked daily at $21.00 \mathrm{~h}$.

Another twelve groups were used for heat exposure at the adult stage. All aphids were reared in the normal day chamber until the eighth day (at $21.00 \mathrm{~h}$ ), and then six groups were moved into the hot day chamber. At $21.00 \mathrm{~h}$ for the next six days, aphid groups in the two chambers were moved to obtain 12 adult treatments that varied in timing and duration (Fig. 1, AE and AL). At $21.00 \mathrm{~h}$ on the $15^{\text {th }}$ day, all aphids were transferred into the normal day chamber and reared until the end of the experiment. The number of offspring and the survival of adults were checked daily at $21.00 \mathrm{~h}$. As a control, a group of aphids was maintained in the normal day chamber until all individuals were dead (Fig. 1, CK). To minimize the effects of plant quality, plants in rearing tubes with aphids were renewed every day during the treatment period of hot days and every 3 days during the maintenance period of normal days.

\subsection{Response variables and analysis}

Apart from a few individuals that died before heat exposure, all aphids were used in the analysis. Lifespan of all individuals was defined as time from birth to death and immediate mortality after heat stress was defined as the death rate during a hot day treatment after a recovery of $24 \mathrm{~h}$. Longevity (time from moulting to death), productivity (total number of nymphs produced) and productivity rate (number of 
nymphs per adult produced per day) were used as demographic variables to estimate effects of the hot events on survival individuals after $24 \mathrm{~h}$ recovery. The effects of exposure on an overall fitness measure $\left(r_{m}\right)$ based on mortality and longevity/reproduction was also calculated with PopTools 3.2.5 ${ }^{63}$.

All statistical tests were performed using SPSS 20 (Chicago, Illinois, USA) or R 3.5.1. Fecundity variables (productivity and productivity rate) met assumptions for normality (Shapiro-Wilks test, $P>0.05$ ) and were therefore analyzed through parametric tests. Effects of timing and duration of heat events on each of the variables were analyzed using two-way ANOVA run with PROC GLM. Because of the significant interaction of timing and duration on traits (see below), we further compared the difference between stress duration periods within each timing treatment using one-way ANOVAs. Posthoc comparisons involved Dunnett or Games-Howell tests depending on whether treatment variances were equal or unequal. To define the impact of duration on the traits, we provide treatment - control means (i.e. control values were set to 0 ).

Overall survivorship (based on lifespan of all individuals including those that died after heat stress) against duration and timing of heat treatments was estimated and differences between timing treatments and the control were compared further by using the Cox regression procedure in the 'survival' and 'car' packages in R. To understand 
further the effects of heat treatments on survivorship, we analyzed immediate mortality after heat stress separately from adult longevity of surviving individuals (delayed mortality). The relationship between duration of hot days and immediate mortality was analyzed by fitting a linear regression model for each timing treatment. The difference between timing treatments in terms of regression slopes and intercepts was determined using one-way analysis of covariance (ANCOVA). Note that we also considered non-linear regressions in these analyses but duration effects were more appropriately treated as linear relationships. The same analysis was undertaken to consider duration effects on $r_{m}$.

\section{RESULTS}

\subsection{Overall effects of heating treatments on survivorship}

Duration had significant impacts on lifespan within the different life stages (Fig. 2; $\mathrm{NE}: Z=4.683, P<0.001 ; \mathrm{NL}: Z=7.122, P<0.001 ; \mathrm{AE}: Z=6.338, P<0.001 ; \mathrm{AL}: Z=$ 6.377, $P<0.001)$. Compared with a mean lifespan $28.5 \pm 8.6$ days for the controls, mean lifespans were shortened the most by heat exposures at the NE stages (Fig2A, 12 - 15.5 days), but less so at the NL (Fig2B, 4 - 14.7 days), AE (Fig2C, 5 - 13.7 days) and AL (Fig2D, 5.5 - 11.5 days) stages. Mortality increased with an extended duration of hot days at all stages except NE; at this stage, even a single hot day was sufficient to sharply decrease survival (Fig. 2).

This article is protected by copyright. All rights reserved. 


\subsection{Immediate effects of heating treatments on survivorship}

Overall, immediate mortality increased linearly with an increase in duration of hot days at all stages (Fig. 3; NE: $R^{2}=0.939, P<0.001$, NL: $R^{2}=0.903, P=0.002$, AE: $\left.R^{2}=0.928, P=0.001, \mathrm{AL}: R^{2}=0.800, P=0.007\right)$. Comparisons between regression lines showed that there were significant differences between regression intercepts $\left(F_{3,19}=\right.$ 12.958, $P<0.001)$ rather than slopes $\left(F_{3,16}=1.633, P=0.221\right)$. A posthoc comparison indicated that only the intercept of the NL treatment differed from the other treatments. Heat stress applied at the NL stage showed lower mortality than in the other treatments. Note that control mortality during the entire period was around $2 \%$.

\subsection{Delayed effects of heating treatments on adult lifespan}

For longevity of surviving adults, there was a significant timing $\times$ duration interaction $(Z=3.542, P<0.001)$. Duration of heat treatments had significant impacts on longevity within the life stages (Fig. 4; NE: $Z=5.660, P<0.001$; NL: $Z=4.928, P<$

0.001; AE: $Z=5.661, P<0.001 ;$ AL: $Z=6.220, P<0.001)$. Compared with a mean longevity of $20.7 \pm 8.6$ days for the controls, mean longevities were reduced at the $\mathrm{NE}$ (Fig.4A, 1.8 - 7.7 days) and NL (Fig4B, 3.1 - 7.3 days) stages, and less so at the AE (Fig4C, $<4.7$ days) and AL (Fig4D, $<3.7$ days) stages. Longer heating treatments 
decreased lifespan at the NL stage, but showed the opposite trend at the NE stage (Fig. 4).

\subsection{Fecundity costs of heating treatments: productivity and productivity rate}

For productivity, there were significant effects of duration $\left(F_{5,573}=3.131, P=0.008\right)$ and an interaction involving timing $\times$ duration $\left(F_{15,573}=1.967, P=0.016\right)$ of hot days but no overall difference in timing treatments $\left(F_{15,573}=1.453, P=0.226\right)$. Unlike for the longevity effects, negative effects of duration in heat stress were evident at all stages (Fig. 5A-5D; NE: $F_{6,178}=3.491, P=0.003$; NL: $F_{6,238}=5.632, P<0.001$; AE: $\left.F_{6,170}=4.709, P<0.001 ; \mathrm{AL}: F_{6,151}=4.235, P=0.001\right)$. Compared with a mean productivity of $44.6 \pm 17.5$ nymphs/adult for the control, productivity was reduced at all stages (Fig.5A-5D; NE: 25.6 - 39.7 nymphs; NL: 27.7 - 43.2 nymphs; AE: 20.4 37.1 nymphs; AL: 26.9 - 39.1 nymphs). The negative effect increased with stress duration except in the case of NE.

There were significant effects of timing $\left(F_{3,573}=32.816, P=0.001\right)$ and an interaction involving timing $\times$ duration $\left(F_{15,573}=1.683, P=0.050\right)$ of heating treatments on productivity rate. In contrast to the other variables, increasing stress duration led to a decreasing productivity rate more strongly in the adult treatments (Fig. $6 \mathrm{C}$ and 6D; AE: $F_{6,170}=12.245, P<0.001$; AL: $F_{6,151}=13.046, P<0.001$ ) than in the nymph treatments (Fig. 6A and 6B; NE: $F_{6,178}=3.649, P=0.002$; NL: $F_{6,238}=$ 
1.066, $P=0.384$ ).Compared with a mean productivity rate $2.5 \pm 0.6$ nymphs/adult/day for the control, productivity rate was reduced by stress particularly at the adult stages (AE:1.3 - 1.9 nymphs/adult/day ; AL: 1.5 - 2.0 nymphs/adult/day), and to a lesser extent at the nymph stages (NE :1.7 - 2.4 nymphs/adult/day; NL:2.1 2.6 nymphs/adult/day).

\subsection{Effect of heat stress on fitness: intrinsic rate of population increase}

Regression analyses indicated that $r_{m}$ declined linearly with an increase of duration of hot days at all stages (Fig. 7; NEs: $R^{2}=0.853, P=0.002$, NLs: $R^{2}=0.871, P=0.001$, AEs: $R^{2}=0.619, P=0.022$, ALs: $\left.R^{2}=0.775, P=0.006\right)$. Comparisons between regression lines showed that there were significant differences between intercepts $\left(F_{3,23}=6.759, P=\right.$ $0.002)$ but not slopes $\left(F_{3,20}=0.772, P=0.523\right)$. A posthoc comparison indicated that only the intercept of the NL treatment differed from the other treatments. Heat stress applied at the NL stages showed higher $r_{m}$ than when applied at the other stages.

\section{DISCUSSION}

Duration of heat treatments did have significant impacts on overall survival (lifespan)

(Fig. 2) and immediate mortalities increased with the duration of heat events (Fig. 3) as expected from a likely increase in lesions with heat intensity/exposure time ${ }^{48}$. This pattern has been documented across taxa ${ }^{64,65}$. The data also indicate differences in stage-specific heat tolerance with a relatively low lethality when only older nymphs 
were exposed, consistent with a previous study which also showed greater sensitivity in adults ${ }^{18}$. This pattern of stage-specific tolerance has been noted in many insects 66-68 including other aphids ${ }^{12,69,70}$. An increase of heat resistance at later instars might be related to the proliferation of facultative symbionts ${ }^{71,72}$ with host age ${ }^{73}$. The low level of adult tolerance might reflect trade-offs between heat tolerance and reproductive output ${ }^{66,74}$ or inherent differences in the capacity for thermo-regulation 75,76

Heat injuries can accumulate and be displayed at later stages which might result in delayed deaths ${ }^{77,78}$ or decreased adult performance ${ }^{18,19,26}$. In our experiment, a comparison of stress duration effects on survivors indicated that adult effects were contingent on exposed life-stage (Fig. 4 - Fig. 6). Heat stress reduced adult longevity when nymphs were exposed, but there were minor effects when adults were exposed (Fig.4). On the other hand, heat exposure at all timing treatments did have substantial effects on productivity (Fig. 5). Long-term heat exposure is known to depress reproduction through a shortened longevity ${ }^{19,56}$, a smaller body size ${ }^{79}$ and/or decreased number of ovarioles ${ }^{80,81}$. Given that the per day reproductive output was decreased following adult exposure, embryo production capacity may be decreased as a result of heat treatment. 
Our results suggest that overall effects of heat stress on fitness are variable and likely involve a number of causes depending on the nature of the stress exposure. While effects from nymph exposures were driven at least partly by reductions in longevity/lifespan, those associated with adult exposure were due to other factors, even if the summed effects of these changes was similar. This highlights the usefulness of dissecting in detail such stress effects. Adult fecundity has previously been found negatively correlated with the total sum (across all life-stages) of heat stress which organisms experience during their entire life-cycle ${ }^{19}$. However, there is an underlying level of complexity that is not covered by such an approach. It is noteworthy that although productivities were reduced as expected with heat duration when adults or older nymphs were exposed, this was not a universal pattern across traits and stages, with increasing heat duration decreasing productivity when the exposed stage involved newly born nymphs, a life stage that is vulnerable to heat ${ }^{18}$.

These results also raise the issue of whether resistant individuals could be selected in different ways when severe heat stress is imposed on sensitive immature stages. Previous studies have demonstrated that heat performance can be increased by local temperature environments ${ }^{82-84}$ or laboratory selection ${ }^{85-88}$ in which stress exposure is chronic ${ }^{85,89}$ or acute stress is imposed at some life-stage, particularly the adult stage $88,90,91$. Our results indicate that stress exposure at one stage has fitness consequences 
at a different stage, so that selection on fitness components at the adult stage could in fact be a consequence of heat events during an early stage in the life cycle of an organism. This suggests a level of complexity in evolutionary responses that needs to be considered when predicting the effects of thermal stress on populations.

In summary, we have shown that heat stress effects are not simply a consequence of exposure duration. While an increase in stress duration generally leads to an increase in negative effects on organisms, there is a level of complexity in this association depending on the life stage exposed and trait under consideration. We have shown that at least in one case an increase in duration improves subsequent performance of a fitness component. This means that measures of heat stress effects need to consider the way in which stress effects are characterized. It remains to be seen what underlying mechanisms drive these different effects.

\section{ACKNOWLEDGMENTS}

We thank Miss Xiu-qin Pei for assistance in completing experiments. This research was supported financially by the National Natural Science Foundation of China (31620103914 and 31272035), the Natural Science Foundation of Shanxi Province (2015011075) and the Foundation in Shanxi Academy of Agricultural Sciences (YBSJJ1512, yydzx16 and YCX2018D2BH5).

\section{REFERENCES}

This article is protected by copyright. All rights reserved. 
1. IPCC. Summary for Policymakers. In Climate change 2013: The physical science basis Contribution of working group I to the fifth assessment report of the intergovernmental panel on climate change, ed. by Stocker TF, D. Qin, G.-K. Plattner, M. Tignor, S.K. Allen, J. Boschung, A. Nauels, Y. Xia, V. Bex and P.M. Midgley. Cambridge University Press: Cambridge, United Kingdom and New York, USA (2013).

2. Ganguly AR, Steinhaeuser K, Erickson DJ, 3rd, Branstetter M, Parish ES, Singh N, Drake JB and Buja L, Higher trends but larger uncertainty and geographic variability in 21 st century temperature and heat waves. P Natl Acad Sci Usa; 106(37): 15555-15559 (2009).

3. Deutsch CA, Tewksbury JJ, Huey RB, Sheldon KS, Ghalambor CK, Haak DC and Martin PR, From the Cover: Impacts of climate warming on terrestrial ectotherms across latitude. P Natl Acad Sci Usa; 105(18): 6668-6672 (2008).

4. Smith MD, An ecological perspective on extreme climatic events: a synthetic definition and framework to guide future research. $J$ Ecol; 99(3): 656-663 (2011).

5. Coumou D and Rahmstorf S, A decade of weather extremes. Nature Climate Change; 2(7): 491-496 (2012).

6. Meehl GA and Tebaldi C, More intense, more frequent and longer lasting heat waves in the 21st century. Science; 305(5686): 994-997 (2004).

7. Kingsolver JG, Diamond SE and Buckley LB, Heat stress and the fitness consequences of climate change for terrestrial ectotherms. Funct Ecol; 27(6): 1415-1423 (2013).

8. Overgaard J, Kearney MR and Hoffmann AA, Sensitivity to thermal extremes in Australian Drosophila implies similar impacts of climate change on the distribution of widespread and tropical species. Glob Change Biol; 20(6): 1738-1750 (2014).

9. Vasseur DA, DeLong JP, Gilbert B, Greig HS, Harley CD, McCann KS, Savage V, Tunney $\mathrm{TD}$ and O'Connor MI, Increased temperature variation poses a greater risk to species than climate warming. P Roy Soc Lond B Bio; 281(1779): 20132612 (2014).

10. Buckley LB and Huey RB, Temperature extremes: geographic patterns, recent changes, and implications for organismal vulnerabilities. Glob Change Biol; 22(12): 3829-3842 (2016).

11. Ma G, Hoffmann AA and Ma C-S, Daily temperature extremes play an important role in predicting thermal effects. J Exp Biol; 218(14): 2289-2296 (2015).

12. Ma CS, Hau B and Poehling HM, The effect of heat stress on the survival of the rose grain aphid, Metopolophium dirhodum (Hemiptera: Aphididae). Eur J Entomol; 101(327-332 (2004).

13. Ma CS, Hau B and Poehling HM, Effects of pattern and timing of high temperature exposure on reproduction of the rose grain aphid, Metopolophium dirhodum. Entomol Exp Appl; 110(1): 65-71 (2004).

14. Blaustein AR, Belden LK, Olson DH, Green DM, Root TL and Kiesecker JM, Amphibian Breeding and Climate Change. Conserv Biol; 15(6): 1804-1809 (2001).

15. Welbergen JA, Klose SM, Markus $\mathrm{N}$ and Eby $\mathrm{P}$, Climate change and the effects of temperature extremes on Australian flying-foxes. P R Soc B; 275(1633): 419-425 (2008). 
16. Friedenberg NA, Sarkar S, Kouchoukos N, Billings RF and Ayres MP, Temperature extremes, density dependence, and southern pine beetle (Coleoptera: Curculionidae) population dynamics in east Texas. Environ Entomol; 37(3): 650-659 (2008).

17. Ma G, Rudolf $\mathrm{VH}$ and Ma Cs, Extreme temperature events alter demographic rates, relative fitness, and community structure. Glob Change Biol; 21(5): 1794-1808 (2015).

18. Zhao F, Hoffmann AA, Xing $\mathrm{K}$ and Ma CS, Life stages of an aphid living under similar thermal conditions differ in thermal performance. J Insect Physiol; 99(1-7 (2017).

19. Zhang W, Rudolf VHW and Ma C-S, Stage-specific heat effects: timing and duration of heat waves alter demographic rates of a global insect pest. Oecologia; 179(4): 947-957 (2015).

20. Berger D, Friberg M and Gotthard K, Divergence and ontogenetic coupling of larval behaviour and thermal reaction norms in three closely related butterflies. $P R$ Soc $B$; 278(1703): 313-320 (2011).

21. Pincebourde $\mathrm{S}$ and Casas J, Warming tolerance across insect ontogeny: influence of joint shifts in microclimates and thermal limits. Ecology; 96(4): 986-997 (2015).

22. Bowler $\mathrm{K}$ and Terblanche JS, Insect thermal tolerance: what is the role of ontogeny, ageing and senescence? Biol Rev; 83(3): 339-355 (2008).

23. Klockmann $\mathrm{M}$, Günter $\mathrm{F}$ and Fischer $\mathrm{K}$, Heat resistance throughout ontogeny: body size constrains thermal tolerance. Glob Change Biol; 23(686-696 (2017).

24. Chen H, Solangi GS, Guo J, Wan F and Zhou Z, Antioxidant responses of ragweed leaf beetle Ophraella communa (Coleoptera: Chrysomelidae) exposed to thermal stress. Frontiers in Physiology; 9 (808 (2018).

25. Folguera G, Mensch J, Muñoz JL, Ceballos SG, Hasson E and Bozinovic F, Ontogenetic stage-dependent effect of temperature on developmental and metabolic rates in a holometabolous insect. J Insect Physiol; 56(11): 1679-1684 (2010).

26. Zhang W, Chang XQ, Hoffmann AA, Zhang S and Ma CS, Impact of hot events at different developmental stages of a moth: the closer to adult stage, the less reproductive output. Scientific Reports; $\mathbf{5}((2015)$.

27. Bürgi LP and Mills NJ, Ecologically relevant measures of the physiological tolerance of light brown apple moth, Epiphyas postvittana, to high temperature extremes. J Insect Physiol; 58(9): 1184-1191 (2012).

28. Zani P, Cohnstaedt L, Corbin D, Bradshaw W and Holzapfel C, Reproductive value in a complex life cycle: heat tolerance of the pitcher-plant mosquito, Wyeomyia smithii. $J$ Evolution Biol; 18(1): 101-105 (2005).

29. Blanckenhorn WU, Gautier R, Nick M, Puniamoorthy N and Schäfer MA, Stage-and sex-specific heat tolerance in the yellow dung fly Scathophaga stercoraria. $J$ Therm Biol; 46(1-9 (2014).

30. Heerwaarden B, Lee R, Wegener B, Weeks A and Sgro C, Complex patterns of local adaptation in heat tolerance in Drosophila simulans from eastern Australia. J Evolution Biol; 25(9): 1765-1778 (2012). 
31. Vorhees AS and Bradley TJ, Differences in critical thermal maxima and mortality across life stages of the mealworm beetle Tenebrio molitor. J Exp Biol; 215(13): 2319-2326 (2012).

32. Knapp M and Nedv d O, Gender and timing during ontogeny matter: effects of a temporary high temperature on survival, body size and colouration in Harmonia axyridis. PLOS One; 8(9): e74984 (2013).

33. Stoks R and Córdoba-Aguilar A, Evolutionary ecology of odonata: A complex life cycle perspective. Annu Rev Entomol; 57(1): 249-265 (2012).

34. McCue MD and De Los Santos R, Upper thermal limits of insects are not the result of insufficient Oxygen delivery. Physiol Biochem Zool; 86(2): 257-265 (2013).

35. Piyaphongkul J, Pritchard J and Bale J, Can tropical insects stand the heat? A case study with the brown planthopper Nilaparvata lugens (Stål). PLOS One; 7(1): e29409 (2012).

36. Schiffer M, Hangartner $\mathrm{S}$ and Hoffmann AA, Assessing the relative importance of environmental effects, carry-over effects and species differences in thermal stress resistance: a comparison of Drosophilids across field and laboratory generations. J Exp Biol; 216(20): 3790-3798 (2013).

37. Aldyhim $\mathrm{Y}$ and Khalil A, Influence of temperature and daylength on population development of Aphis gossypii on Cucurbita pepo. Entomol Exp Appl; 67(2): 167-172 (1993).

38. Xing K, Hoffmann AA and Ma C-S, Does thermal variability experienced at the egg stage influence life history traits across life cycle stages in a small invertebrate? PLOS One; 9(6): e99500 (2014).

39. Xing K, Ma CS, Zhao F and Han JC, Effects of large temperature fluctuations on hatching and subsequent development of the diamondback moth (Lepidoptera: Plutellidae). Fla Entomol; 98(2): 651-659 (2015).

40. Klockmann M, Kleinschmidt F and Fischer K, Carried over: Heat stress in the egg stage reduces subsequent performance in a butterfly. PLOS One; 12(7): e0180968 (2017).

41. MacLean HJ, Kristensen TN, Overgaard J, Sørensen JG and Bahrndorff S, Acclimation responses to short-term temperature treatments during early life stages causes long lasting changes in spontaneous activity of adult Drosophila melanogaster. Physiol Entomol; 42(4): 404-411 (2017).

42. Arambourou H, Sanmartínvillar I and Stoks R, Wing shape-mediated carry-over effects of a heat wave during the larval stage on post-metamorphic locomotor ability. Oecologia; 184(1): 279-291 (2017).

43. Bozinovic F and Pörtner HO, Physiological ecology meets climate change. Ecology \& Evolution; 5(5): 1025-1030 (2015).

44. Kingsolver JG, Woods HA, Buckley LB, Potter KA, MacLean HJ and Higgins JK, Complex life cycles and the responses of insects to climate change. Integr Comp Biol; 51(5): 719-732 (2011).

45. Carey JR, Insect biodemography. Annu Rev Entomol; 46(1): 79 (2001). 
46. Kingsolver JG and Woods HA, Beyond thermal performance curves: Modeling time-dependent effects of thermal stress on ectotherm growth rates. Am Nat; 187(3): 283 (2016).

47. Roitberg BD and Mangel M, Cold snaps, heatwaves, and arthropod growth: Thermal performance of arthropods under stress. Ecol Entomol; 41(6): 653-659 (2016).

48. Denlinger DL and Yocum GD. Physiology of heat sensitivity. In Temperature sensitivity in insects and application in integrated pest management, ed. by Hallman GJ and Denlinger DL. Westview Press Oxford: London, pp. 7-53 (1998).

49. Bozinovic F, Sabat P, Rezende EL and Canals M, Temperature variability and thermal performance in ectotherms: acclimation, behaviour, and experimental considerations. Evol Ecol Res; 17(1): 111-124 (2016).

50. Bozinovic F, Bastías DA, Boher F, Clavijo-Baquet S, Estay SA and Angilletta MJ, The mean and variance of environmental temperature interact to determine physiological tolerance and fitness. Physiol Biochem Zool; 84(6): 543-552 (2011).

51. Cavieres G, Bogdanovich JM, Toledo P and Bozinovic F, Fluctuating thermal environments and time - dependent effects on fruit fly egg - hatching performance. Ecology \& Evolution; 8(14): 7014-7021 (2018).

52. Bozinovic F, Medina NR, Alruiz JM, Cavieres G and Sabat P, Thermal tolerance and survival responses to scenarios of experimental climatic change: changing thermal variability reduces the heat and cold tolerance in a fly. Journal of Comparative Physiology B-biochemical Systemic \& Environmental Physiology; 186(5): 581-587 (2016).

53. Bozinovic F, Catalan TP, Estay SA and Sabat P, Acclimation to daily thermal variability drives the metabolic performance curve. Evol Ecol Res; 15(5): 579-587 (2013).

54. Clavijo-Baquet S, Boher F, Ziegler L, Martel SI, Estay SA and Bozinovic F, Differential responses to thermal variation between fitness metrics. Scientific Reports; 4(1): 5349 (2015).

55. Sentis A, Hemptinne JL and Brodeur J, Effects of simulated heat waves on an experimental plant-herbivore-predator food chain. Glob Change Biol; 19(3): 833-842 (2013).

56. Zhao F, Zhang W, Hoffmann AA and Ma CS, Night warming on hot days produces novel impacts on development, survival and reproduction in a small arthropod. $J$ Anim Ecol; 83(4): 769-778 (2014).

57. Clusella-Trullas S, Blackburn TM and Chown SL, Climatic predictors of temperature performance curve parameters in ectotherms imply complex responses to climate change. $\mathrm{Am}$ Nat; 177(6): 738-751 (2011).

58. Paaijmans KP, Heinig RL, Seliga RA, Blanford JI, Blanford S, Murdock CC and Thomas MB, Temperature variation makes ectotherms more sensitive to climate change. Glob Change Biol; 19(8): 2373-2380 (2013).

59. Colinet H, Sinclair BJ, Vernon $\mathrm{P}$ and Renault $\mathrm{D}$, Insects in fluctuating thermal environments. Annu Rev Entomol; 60(123-140 (2015). 
60. Dawson TP, Jackson ST, House JI, Prentice IC and Mace GM, Beyond predictions: Biodiversity conservation in a changing climate. Science; 332(6025): 53-58 (2011).

61. Emden HFv and Harrington R. Aphids as crop pests. CABI, (2007).

62. Asin L and Pons X, Effect of high temperature on the growth and reproduction of corn aphids (Homoptera: Aphididae) and implications for their population dynamics on the northeastern Iberian peninsula. Environ Entomol; 30(6): 1127-1134 (2001).

63. Hood GM, PopTools version 3.2.5. Available on the internet. URL http://wwwpoptoolsorg (2011).

64. Mislan KAS, Helmuth B and Wethey DS, Geographical variation in climatic sensitivity of intertidal mussel zonation. Global Ecol Biogeogr; 23(7): 744-756 (2014).

65. Kjærsgaard A, Demontis D, Kristensen TN, Le N, Faurby S, Pertoldi C, Sørensen JG and Loeschcke V, Locomotor activity of Drosophila melanogaster in high temperature environments: plastic and evolutionary responses. Clim Res; 43(1): 127-134 (2010).

66. Lyons CL, Coetzee M, Terblanche JS and Chown SL, Thermal limits of wild and laboratory strains of two African malaria vector species, Anopheles arabiensis and Anopheles funestus. Malaria J; 11(226): 10.1186 (2012).

67. Klok CJ and Chown SL, Critical thermal limits, temperature tolerance and water balance of a sub-Antarctic kelp fly,Paractora dreuxi (Diptera: Helcomyzidae). J Insect Physiol; 47(1): 95-109 (2001).

68. Chavadi VB, Sosalegowda AH and Boregowda MH, Impact of heat shock on heat shock proteins expression, biological and commercial traits of Bombyx mori. Insect Sci; 13(4): 243-250 (2006).

69. Kaakeh W and Dutcher JD, Survival of yellow pecan aphids and black pecan aphids (Homoptera: Aphididae) at different temperature regimes. Environ Entomol; 22(4): 810-817 (1993).

70. Harrison J and Barlow C, Survival of the pea aphid, Acyrthosiphon pisum (Homoptera: Aphididae), at extreme temperatures. Can Entomol; 105(12): 1513-1518 (1973).

71. Montllor CB, Maxmen A and Purcell AH, Facultative bacterial endosymbionts benefit pea aphids Acyrthosiphon pisum under heat stress. Ecol Entomol; 27(2): 189-195 (2002).

72. Oliver KM, Degnan PH, Burke GR and Moran NA, Facultative symbionts in aphids and the horizontal transfer of ecologically important traits. Annu Rev Entomol; 55(1): 247-266 (2010).

73. Laughton AM, Fan MH and Gerardo NM, The combined effects of bacterial symbionts and aging on life history traits in the pea aphid, Acyrthosiphon pisum. Appl Environ Microb; 80(2): 470-477 (2014).

74. Cox RM, Parker EU, Cheney DM, Liebl AL, Martin LB and Calsbeek R, Experimental evidence for physiological costs underlying the trade-off between reproduction and survival. Funct Ecol; 24(6): 1262-1269 (2010).

75. Ma G and Ma CS, Climate warming may increase aphids' dropping probabilities in response to high temperatures. J Insect Physiol; 58(11): 1456-1462 (2012). 
76. Ma G and Ma CS, Effect of acclimation on heat-escape temperatures of two aphid species: Implications for estimating behavioral response of insects to climate warming. $J$ Insect Physiol; 58(3): 303-309 (2012).

77. Mironidis GK and Savopoulou-Soultani M, Effects of heat shock on survival and reproduction of Helicoverpa armigera (Lepidoptera: Noctuidae) adults. J Therm Biol; 35(2): 59-69 (2010).

78. Xie Q, Hou B and Zhang R, Thermal responses of oriental fruit fly (Diptera: Tephritidae) late third instars: mortality, puparial morphology, and adult emergence. J Econ Entomol; 101(3): 736-741 (2008).

79. Stillwell RC and Fox CW, Complex patterns of phenotypic plasticity: interactive effects of temperature during rearing and oviposition. Ecology; 86(4): 924-934 (2005).

80. Bader CA and Williams CR, Mating, ovariole number and sperm production of the dengue vector mosquito Aedes aegypti (L.) in Australia: broad thermal optima provide the capacity for survival in a changing climate. Physiol Entomol; 37(2): 136-144 (2012).

81. Hodin J. She shapes events as they come: plasticity in female insect reproduction. Science Publishers, Inc. Enfield, New Hampshire, USA, (2009).

82. Diaz F, Munoz-Valencia V, Juvinao-Quintero DL, Manzano-Martinez MR, Toro-Perea N, Cardenas-Henao $\mathrm{H}$ and Hoffmann AA, Evidence for adaptive divergence of thermal responses among Bemisia tabaci populations from tropical Colombia following a recent invasion. $J$ Evolution Biol; 27(6): 1160-1171 (2014).

83. Willi Y and Hoffmann AA, Microgeographic adaptation linked to forest fragmentation and habitat quality in the tropical fruit fly Drosophila birchii. Oikos; 121(10): 1627-1637 (2012).

84. Sgo CM, Heerwaarden Bv, Kellermann V, Wee CW, Hoffmann AA and Lee SF, Complexity of the genetic basis of ageing in nature revealed by a clinal study of lifespan and methuselah, a gene for ageing, in Drosophila from eastern Australia. Mol Ecol; 22(13): 3539-3551 (2013).

85. Cavicchi S, Guerra D, Torre V and Huey RB, Chromosomal analysis of heat-shock tolerance in Drosophila melanogaster evolving at different temperatures in the laboratory. Evolution; 49(4): 676-684 (1995).

86. Gilchrist GW and Huey RB, The direct response of Drosophila melanogaster to selection on knockdown temperature. Heredity; 83(1): 15-29 (1999).

87. Hoffmann AA, Dagher H, Hercus M and Berrigan D, Comparing different measures of heat resistance in selected lines of Drosophila melanogaster. J Insect Physiol; 43(4): 393-405 (1997).

88. Bubliy OA and Loeschcke V, Correlated responses to selection for stress resistance and longevity in a laboratory population of Drosophila melanogaster. J Evolution Biol; 18(4): 789-803 (2005).

89. Magiafoglou A and Hoffmann A, Thermal adaptation in Drosophila serrata under conditions linked to its southern border: Unexpected patterns from laboratory selection suggest limited evolutionary potential. J Genet; 82(3): 179-189 (2003). 
90. Kristensen TN, Loeschcke V and Hoffmann AA, Can artificially selected phenotypes influence a component of field fitness? Thermal selection and fly performance under thermal extremes. P R Soc B; 274(1611): 771-778 (2007).

91. Folk DG, Zwollo P, Rand DM and Gilchrist GW, Selection on knockdown performance in Drosophila melanogaster impacts thermotolerance and heat-shock response differently in females and males. J Exp Biol; 209(20): 3964-3973 (2006). 
Figure 1 Schematic diagram of experimental design (a 16-day long section). Four periods were identified with six duration patterns (NE1-6, NL1-6, AE1-6 and AL1-6) within each period. During the experiment, aphids were maintained as normal (blue bars) except for the periods of hot day treatments (red bars). Adult fitness components were measured on survivors.

Figure 2. Survival curves of all individuals in heating treatments applied at different stages of $S$. avenae. Exposure stages: $\mathrm{NE}=$ early nymph; $\mathrm{NL}=$ late nymph; $\mathrm{AE}=$ early adult; $\mathrm{AL}=$ late adult.

Figure 3. Association between heating treatments at each timing stage and immediately mortality during stress in $S$. avenae. Solid lines indicate linear regressions. Exposure stages: $\mathrm{NE}=$ early nymph; $\mathrm{NL}=$ late nymph; $\mathrm{AE}=$ early adult; $\mathrm{AL}=$ late adult.

Figure 4. Survival curves of longevity of survival individuals in heating treatments applied at different stages of $S$. avenae. Exposure stages: $\mathrm{NE}=$ early nymph; $\mathrm{NL}=$ late nymph; $\mathrm{AE}=$ early adult; $\mathrm{AL}=$ late adult.

Figure 5. Change in productivity (mean $\pm \mathrm{SE}$ ) in heating treatments at different stages of $S$. avenae. The "*” symbol represents a significant difference between each duration group and control group at the $P<0.05$ level based on multiple comparisons (Dunnett or Games-Howell). Treated stages are plotted separately for NE = early nymph, $\mathrm{NL}=$ late nymph, $\mathrm{AE}=$ early adult, $\mathrm{AL}=$ late adult.

Figure 6 . Change in productivity rate (mean $\pm \mathrm{SE}$ ) in heating treatments at different stages of $S$. avenae. See Figure 5 legend for explanation.

Figure 7. Linear regressions between intrinsic rate of population increase $\left(r_{m}\right)$ and duration of hot days at different stages. Exposure stages: $\mathrm{NE}=$ early nymph; $\mathrm{NL}=$ late nymph; $\mathrm{AE}=$ early adult; $\mathrm{AL}=$ late adult. 
The importance of timing of heat events for predicting the dynamics of aphid pest populations

Fei Zhao ${ }^{*}$ Kun Xing Ary A. Hoffmann and Chun-sen Ma*

An interaction between timing and duration of heat wave is driving complex impacts on different fitness components and means its importance for predicting the dynamics of aphid pest populations. 


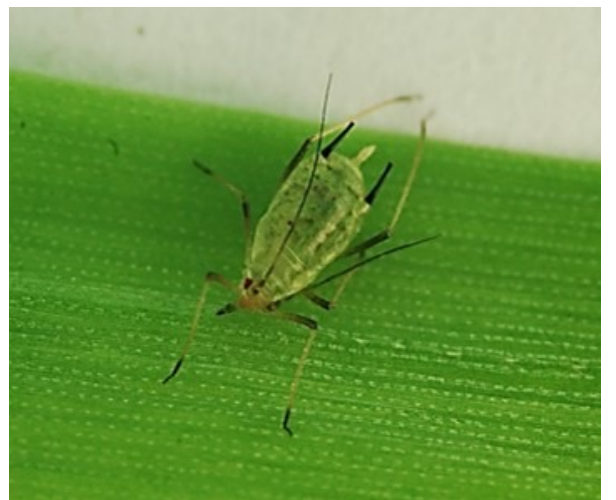

PS_5344_Graphical Figure.jpg

This article is protected by copyright. All rights reserved. 


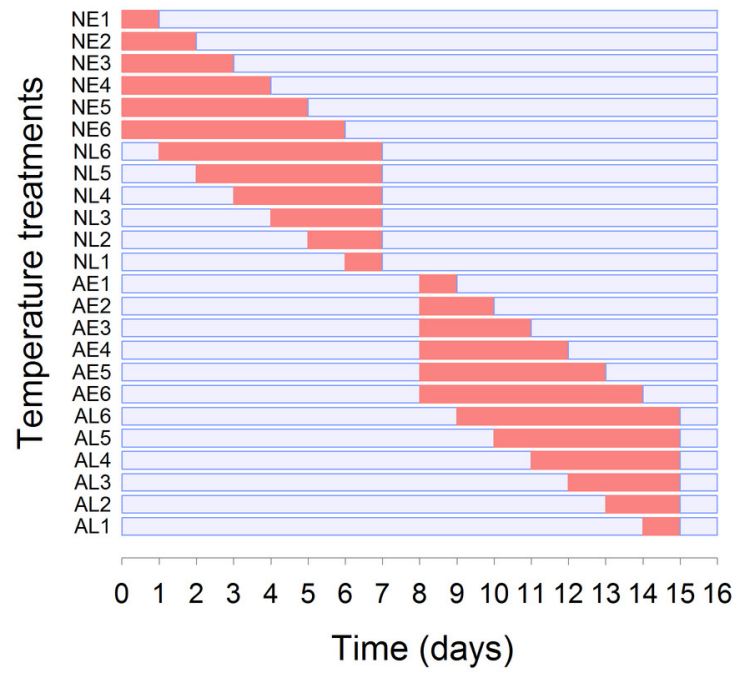

PS_5344_Fig.1 Experimental design.JPG

This article is protected by copyright. All rights reserved. 


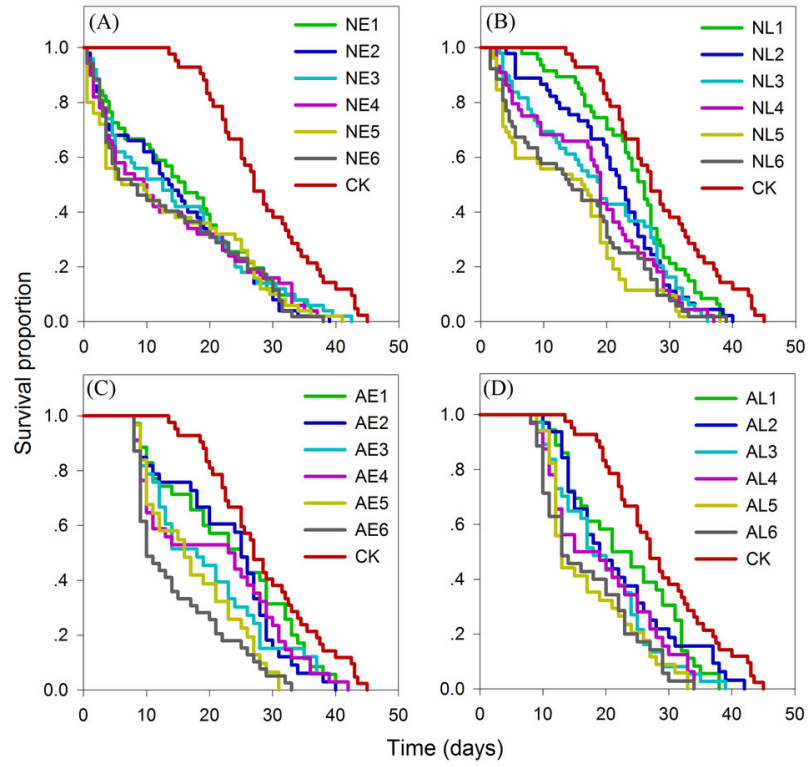

PS_5344_Fig.2 lifespan.JPG 


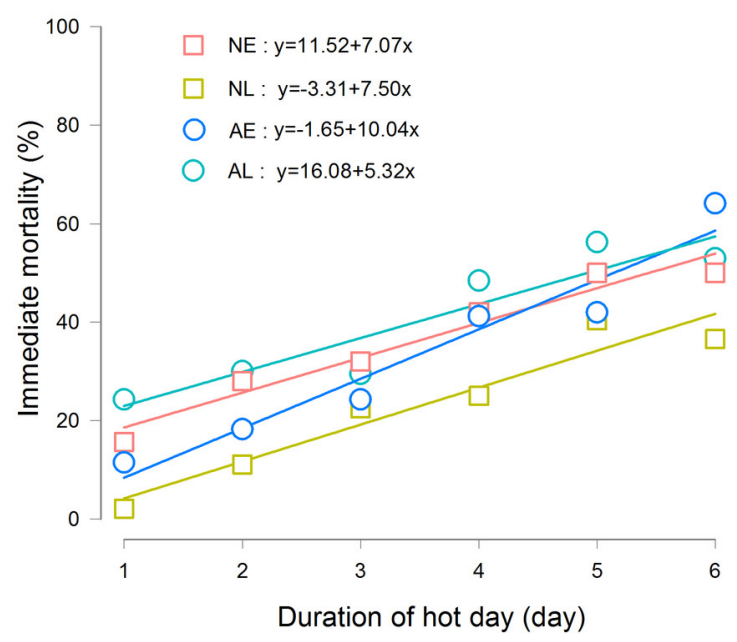

PS_5344_Fig.3 Mortality.JPG

This article is protected by copyright. All rights reserved. 


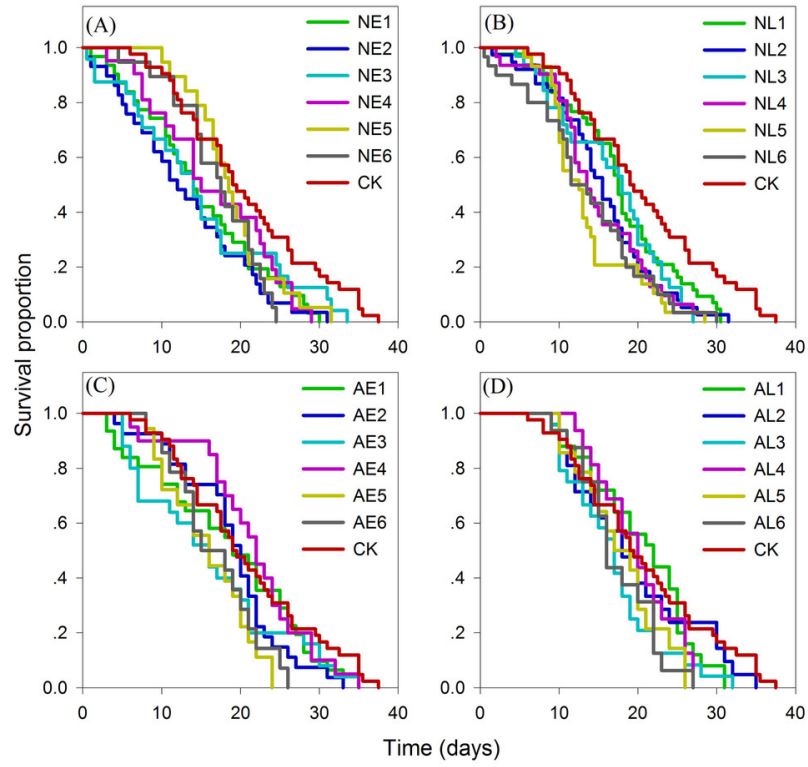

PS_5344_Fig.4 longevity.JPG

This article is protected by copyright. All rights reserved. 


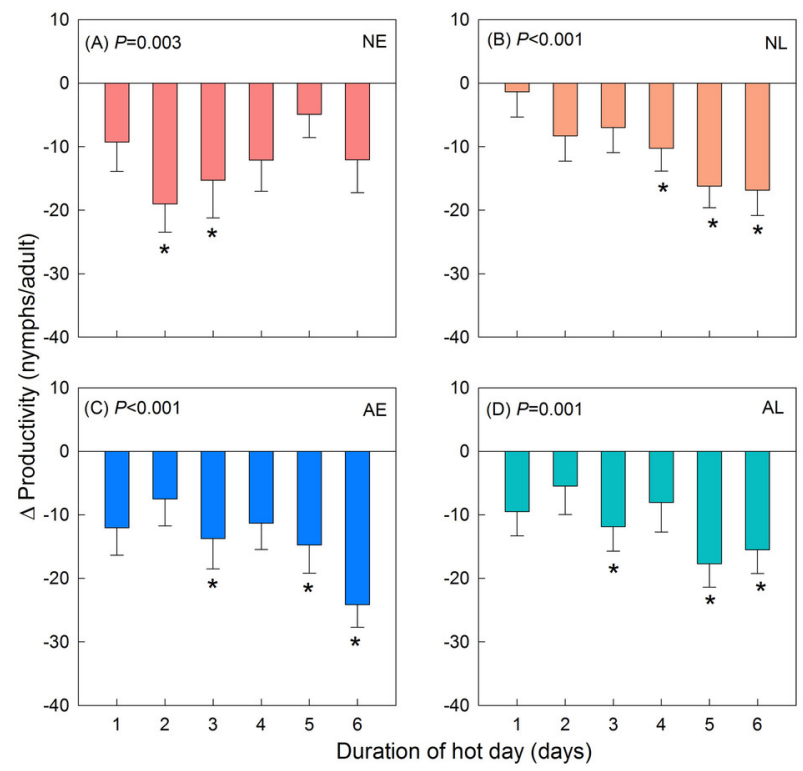

PS_5344_Fig.5 Productivity.JPG

This article is protected by copyright. All rights reserved. 


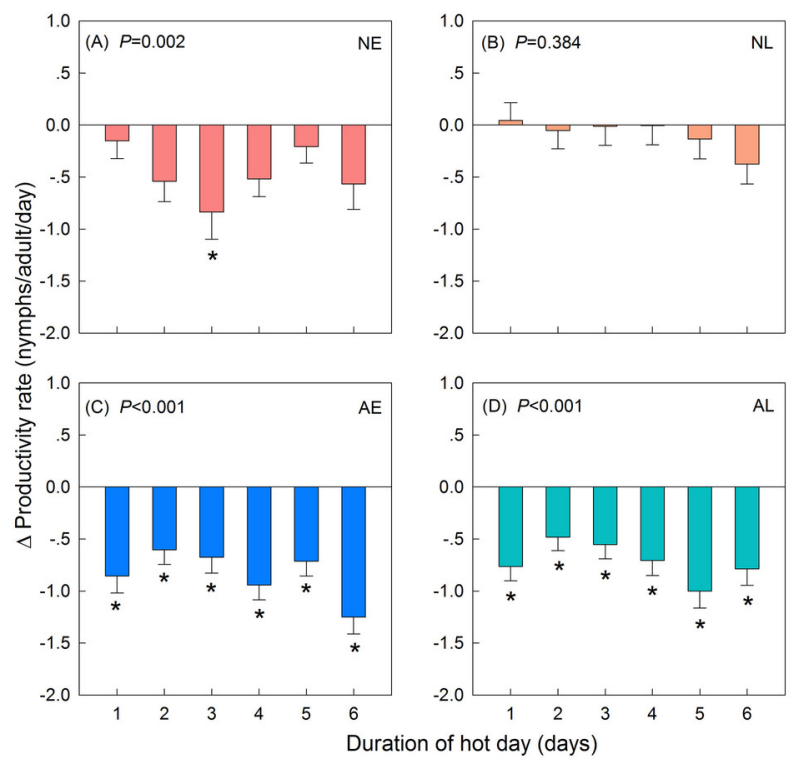

PS_5344_Fig.6 Productivity rate.JPG

This article is protected by copyright. All rights reserved. 


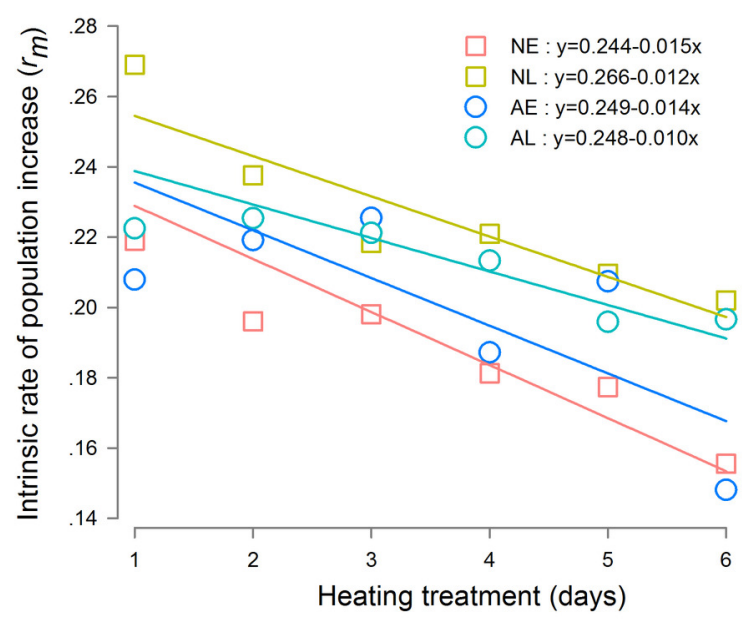

PS_5344_Fig.7 Intrinsic rate of population increase.JPG

This article is protected by copyright. All rights reserved. 


\section{University Library}

\section{- M M I N E R VA A gateway to Melbourne's research publications}

Minerva Access is the Institutional Repository of The University of Melbourne

Author/s:

Zhao, F;Xing, K;Hoffmann, AA;Ma, C-S

Title:

The importance of timing of heat events for predicting the dynamics of aphid pest populations

Date:

2019-07-01

\section{Citation:}

Zhao, F., Xing, K., Hoffmann, A. A. \& Ma, C. -S. (2019). The importance of timing of heat events for predicting the dynamics of aphid pest populations. PEST MANAGEMENT SCIENCE, 75 (7), pp.1866-1874. https://doi.org/10.1002/ps.5344.

Persistent Link:

http://hdl.handle.net/11343/285557 